\title{
Genotypes and phenotypes
}

All is but lip wisdom which wants experience. —Sir Philip Sydney

John Wayne experienced two separate episodes of an alarming pulmonary lesion late in life. After the first was successfully resected, he boasted that he had licked "the big C." In retrospect, he probably licked "the little h," i.e., hamartoma. The second lesion was indeed a malignancy. In his optimism, though, Mr. Wayne epitomized the can-do attitude of those who rode the war wagon against cancer and likened victory in this theater to putting a man on the moon. Successes against some malignancies, such as basal cell carcinoma, acute lymphocytic leukemia, and seminoma, were indeed realized, although cancer warriors never achieved the status of the undefeated. They did, however, create a patchwork of therapies which effectively counter a host of specific tumors.

Three decades ago, when DNA technology was growing in scope and applications, gurus predicted that gene therapy would be operational within 10 years and would revolutionize medical therapeutics. Time and experience have now made us more sage and circumspect in our counsel; we know that we must select appropriate modes and targets of gene therapy. Clearly, the applications of this technique will prove more limited than originally conceived.

Now it is time to understand the proper place in genetics for correlation of genotype and phenotype, originally hoped to provide an accurate prediction of clinical manifestations based upon a specific mutation or type of mutation. The correctness of this relationship appeared intuitively obvious, especially for disorders in which a panoply of clinical effects accompanied a large deletion while near normalcy was associated with a single base change. It was easy to embrace the concept that mutations affecting a critical region of an enzyme, carrier, or receptor would be more harmful than those limited to noncritical or "spacer" regions. The correlation between alterations of a specific domain of a molecule and consequent cellular dysfunction has been elegantly illustrated by studying mutations in the LDL receptor, and any recent literature search will reveal scores of disorders which exhibit some relationship between a specific mutation and a set of clinical manifestations.

On the other hand, recent knowledge and experience argue against a strict correlation between mutation and phenotype. Many biochemical steps lurk between an abnormal nucleotide sequence and its consequent clinical dysfunction. These include replication, repair, transcription, splicing, translation, protein modification, targeting, processing, and compartmentalization. Any of these operations can be affected by modifiers which exert different degrees of influence in different individuals. For example, variable degrees of DNA repair can mute or exacerbate the effects of mutations, differential expression of the spliceosome machinery can drastically affect the severity of splice site mutations, the integrity of O-linked and $\mathrm{N}$-linked glycosylation can significantly influence the ability of mutant proteins to function, and the proper operation of editing processes within the ER determines whether abnormal proteins will be retained or released. Even single gene disorders such as glycerol kinase deficiency are more complex than originally thought and display blurred genotype/phenotype relationships. ${ }^{1}$

Sometimes, too, the very bases of our assumptions about expected phenotypes are incorrect. We might think that mutations in the active site of an enzyme are the most critical, but distant changes that remove or create a salt bridge can change the enzyme's conformation and eliminate the active site. In carrier proteins, mutations in transmembrane residues are considered most severe, but alterations outside a transmembrane region can alter the ability of nearby hydrophobic residues to enter the membrane and this feature destroys transport function. One might expect that deletions or nonsense mutations that produce no mRNA because of nonsense-mediated decay $^{2}$ are worse than point mutations allowing residual mRNA expression. However, in certain disorders such as osteogenesis imperfecta, where the final collagen product consists of trimeric subunits, complete absence of a product actually produces a milder phenotype than residual amounts of an abnormal monomer which renders all trimers nonfunctional. ${ }^{3}$

Consequently, "the broad spectrum of clinical presentations" associated with diseases such as the congenital disorders of glycosylation (CDG) is not as surprising as Westphal et al. aver in this issue of Genetics in Medicine. ${ }^{4}$ The collection of disorders known as CDG all exhibit abnormal N-linked glycosylation, but the defective enzymatic reaction can occur anywhere in the synthesis of glycoproteins, from the lipid-linked precursor to the final, fully processed complex form. ${ }^{5}$ These many different enzyme defects result in a range of clinical manifestations, but even a single deficiency such as that of phosphomannomutase (PMM) can present with different degrees of clinical severity. This finding occurs for several of the reasons noted above as well as because of issues specific to PMM dysfunction. For example, although the PMM-deficient genotype can be readily established by sequencing, its cellular consequences are not well assessed by either $E$. coli $^{6}$ or yeast ${ }^{4}$ expression studies. Such investigations reveal impaired enzyme activity for mild PMM mutants, but normal lipid-linked oligosaccharides and glycosylation efficiencies in cultured fibroblasts with the same mutations. The enzyme assay itself contributes to the uncertainty; fibroblasts of patients 1 and 2 have PMM activities at $25^{\circ} \mathrm{C}$, which are within two standard deviations of the mean for controls. Indeed, on the basis of PMM activity, most heterozygotes are indistinguishable from normal, and some cannot be differentiated from affected individuals. Proceeding to the phenotype, mildly affected patients 
have developmental delay with ataxia and titubation and anatomic abnormalities ranging from "slight cerebellar asymmetry" to "hypoplasia of the cerebellar hemispheres and vermis." The difference between the findings in these mildly affected patients and those in other published cases of CDG type Ia would appear difficult to quantitate. These problems, along with the issues of modifying genes, threshhold effects, and environmental stresses noted by Westphal et al. ${ }^{4}$ suggest that genotype/phenotype correlations in CDG will be characterized more by exceptions than by rules.

Over time, the scientific community has appropriately welcomed new concepts, including genotype/phenotype correlation, with the enthusiasm of a neophyte. Now, we must assess this hypothesis with a different face, grizzled by two decades of experience. To be sure, many of the broad strokes relating genotype to clinical manifestations remain on the canvas. For example, the number of trinucleotide repeats in genes causing certain neurological disorders correlates with the severity of disease. ${ }^{7}$ Two severe mutations in CTNS cause nephropathic cystinosis, while the combination of a mild and a severe mutation result in ocular or late-onset cystinosis. ${ }^{89}$ Specific mutations are known to result in the thiamine-responsive forms of branched-chain $\alpha$-keto acid dehydrogenase deficiency ${ }^{10}$ and in the pyridoxine-responsive form of cystathionine $\beta$-synthase deficiency. ${ }^{11}$ The grace notes, however, are missing, and that brings us to the profound and immutable words of the Duke, "A man's gotta do what a man's gotta do." Gene by gene, mutation by mutation, we must determine through experience the limits and the applications of genotype/phenotype correlation. That will require true grit.
William A. Gahl, MD, PhD

Section on Human Biochemical Genetics Heritable Disorders Branch National Institute of Child Health and Human Development National Institutes of Health Bethesda, Maryland

\section{References}

1. Dipple KM, Zhang YH, Huang BL, McCabe LL, Dallongeville J, Inokuchi T, Kimura M, Marx HJ, Roederer GO, Shih V, Yamaguchi S, Yoshida I, McCabe ER. Glycerol kinase deficiency: evidence for complexity in a single gene disorder. Hum Genet 2001;109:55-62.

2. Frischmeyer PA, Dietz HC. Nonsense-mediated mRNA decay in health and disease. Hum Mol Genet 1999;8:1893-1900.

3. Forlino A, Marini JC. Osteogenesis imperfecta: prospects for molecular therapeutics. Mol Genet Metab 2000;71:225-232.

4. Westphal V, Peterson S, Patterson M, Tournay A, Blumenthal A, Treacy EP, Freeze HH. Functional significance of $P M M 2$ mutations in mildly affected patients with congenital disorders of glycosylation Ia. Genet Med 2001;6:393-398.

5. Krasnewich D, Gahl WA. Carbohydrate-deficient glycoprotein syndrome. Adv Pediatr 1997;44:109-140.

6. Babovic-Vuksanovic D, Patterson MC, Schwenk WF, O'Brien JF, Vockley J, Freeze $\mathrm{HH}$, Mehta DP, Michels VV. Severe hypoglycemia as a presenting symptom of carbohydrate-deficient glycoprotein syndrome. J Pediatr 1999;135:775-781.

7. Timchenko LT, Caskey CT. Trinucleotide repeat disorders in humans: discussions of mechanisms and medical issues. FASEB J 1996;10:1589-1597.

8. Thoene J, Lemons R, Anikster Y, Mullet J, Paelicke K, Lucero C, Gahl W, Schneider J, Shu SG, Campbell HT. Mutations of CTNS causing intermediate cystinosis. Mol Genet Metab 1999;67:283-293.

9. Anikster Y, Lucero C, Guo J, Huizing M, Shotelersuk V, Bernardini I, McDowell G, Iwata F, Kaiser-Kupfer MI, Jaffe R, Thoene J, Schneider JA, Gahl WA. Ocular nonnephropathic cystinosis: clinical, biochemical, and molecular correlations. Pediatr Res 2000;47:17-23.

10. Chuang DT, Shih VE. Maple Syrup Urine Disease (branched-chain ketoaciduria). In: Scriver CR, Beaudet AL, Sly WS, Valle D, editors. The metabolic and molecular bases of inherited disease. New York: McGraw-Hill, 2001:1971-2005.

11. Mudd SH, Levy HL, Kraus JP. Disorders of transsulfuration. In: Scriver CR, Beaudet AL, Sly WS, Valle D, editors. The metabolic and molecular bases of inherited disease. New York: McGraw-Hill, 2001:2005-2056. 